\title{
Application of Determinacy Analysis to the Study of Citizen Satisfaction with the Service-Based Public Management
}

Yuri G. Dmitriev

Svetlana E. Martynova

Peter F. Tarassenko

Yuri K. Ustinov

Tomsk State University, Tomsk, Russia

Doi:10.5901/mjss.2015.v6n6s2p444

\begin{abstract}
The purpose of the article is developing methods of calculating quantitative characteristics of public satisfaction with the activities of the local self-government, as well as with quality of public services provided at the municipality. We suppose that initial data are provided by a sociological survey of the population of the municipal district. Data processing is performed using the determinacy analysis and based on the calculation of variety of conditional frequencies of some properties in the context of other properties. Determinacy analysis provides an extension of regular technique. Along with calculation of the level of satisfaction with a service in a particular group of respondents (intensity), it uses a percentage of satisfaction which is explained by contribution of the particular group (capacity). The joint usage of intensity and capacity enrich and make more complete the interpretation of a survey data. In addition, we propose a technique for evaluation and usage of significance of individual answers. As a result we can adjust the intensity and capacity for extraction of useful information and for the better description of regularities observed in the survey data.
\end{abstract}

Keywords: public services, determinacy analysis, evaluation of satisfaction, sociological survey.

\section{Introduction}

Currently, social scientists discuss the issue of quantitative and qualitative assessment of satisfaction and dissatisfaction of a society with the quantity and quality of provided public services, see, for example, Hoxley (2001), CuadradoBallesteros (2013), Djellal (2013), Purcărea (2013), Umegaki (2014), Martynova (2014), Dmitriev (2015). In Russia, this problem is raised to the level of state objectives by the Presidential Decree of April 28, 2008 No 607 "On the evaluation of the effectiveness of local government of urban and municipal districts" and the Governmental Decree of September 11, 2008 No 1313-p. According to these documents, with the help of a sociological survey of the population of the urban district (municipal district) it is necessary to track the level of public satisfaction with the activities of the local government of urban district (municipal district), as well as with public services provided at the municipal level. The list contains most popular and significant services: health care, general education, pre-school education, additional education of children, services in the field of culture, housing services.

The most objective method of solving this problem is to conduct a survey in the community. To this purpose, the questionnaire is using to collect respondents assessment of the quantity and quality of certain services. Preparation of completed questionnaires to the processing is reduced to the labeling of positive responses with +1 , negative responses with -1 , and neutral responses with 0 . In this paper, along with the classical scheme of processing of the resulting digitized table of questionnaires, which we consider the first, we describe and apply our own technique which is of interest to sociologists in our view.

\section{Classical Scheme of Processing}

The classical technique uses the calculation of relative frequencies of occurrence of different features in the context of other features. Undoubtedly, these estimates make possible to detect a number of important properties of the community. However, these properties may be better described by the analysis of determinations. The theory of determinacy analysis 
is described in the book by S.V.Chesnokov (1982) and used for discovering regularities in sociological, medical, linguistic data, Chesnokov (1991), Luelsdorff (1996), Lind (2008). A short review can be found in the paper by Lind and Kuusik (2008).

Considering a given pair of features $a$ and $b$ in terms of their joint occurrence in a sequence of observations, S.V.Chesnokov suggested to characterize regularity (rule) $a \rightarrow b$ by two numbers,

$$
I(a \rightarrow b)=\frac{N(a b)}{N(a)} \quad \text { and } \quad C(a \rightarrow b)=\frac{N(a b)}{N(b)},
$$

where $N(a), N(b)$, and $N(a b)$ are numbers of those members of community who respectively demonstrate features $a, b$, and both $a b$. The rule $a \rightarrow b$ is called determination, where the feature $a$ is determinative, the feature $b$ is determinable. The relative frequency $I(a \rightarrow b)$ is referred to as intensity (or accuracy) of determination, which measures contribution of $a$ to emergence of $b$. The value of $C(a \rightarrow b)$ is called capacity (or completeness) of determination, $a$ measure of contribution of $b$ to appearance of $a$. The description of the properties of society in terms of the determinations was called determinacy analysis.

We should note that the tradition of wide usage of the relative frequencies of events in context of other events in the form of conditional probability goes back to Kolmogorov (1956). Considering the entire society as a classical probability space we can perceive intensity $I(a \rightarrow b)$ and capacity $C(a \rightarrow b)$ as the estimators of conditional probabilities $\mathrm{P}(b \mid a)$ and $\mathrm{P}(a \mid b)$. So the determinacy analysis differs from the classical theory of probability by joint usage of both conditional probabilities mentioned above. Furthermore, the features $a$ and $b$ in the determination $a \rightarrow b$ play different roles in determinacy analysis (driving and driven feature), while in the theory of probability the events $a$ and $b$ have completely equivalent role in the conditional probabilities $\mathrm{P}(b \mid a)$ and $\mathrm{P}(a \mid b)$.

Now let a questionnaire contains $n+m$ questions, first $n$ of which intended to be used for evaluation of services, and the last $m$ questions are for information, in which respondents report some useful personal information about themselves.

Denote evaluation results through $b_{1}, b_{2}, \ldots, b_{n}$ and put them together in a set $b=\left\{b_{1}, b_{2}, \ldots, b_{n}\right\}$. We will refer to element of the set as "assessment". The personal information on respondents may be denoted by $a_{1}, a_{2}, \ldots, a_{m}$. Elements and subsets of the set $a=\left\{a_{1}, a_{2}, \ldots, a_{m}\right\}$ we will call "group of respondents" or simply "group".

Consider the case when the individual "satisfaction" is assessed using three levels: positive, negative, and neutral. According to determinacy analysis approach we can measure the satisfaction of community (or a part of community, a group) by intensity and capacity of three determinations " group $\rightarrow$ positive", " group $\rightarrow$ negative", " group $\rightarrow$ neutral". It gives us the following values to analyze:

$$
\begin{aligned}
& \mathrm{U}_{+}=\mathrm{I}(\text { group } \rightarrow \text { positive }), \mathrm{V}+=\mathrm{C}(\text { group } \rightarrow \text { positive }), \\
& \mathrm{U}_{-}=\mathrm{I}(\text { group } \rightarrow \text { negative }), \mathrm{V}-=\mathrm{C}(\text { group } \rightarrow \text { negative }), \\
& \mathrm{U}_{0}=\mathrm{I}(\text { group } \rightarrow \text { neutral }), \mathrm{V} 0=\mathrm{C}(\text { group } \rightarrow \text { neutral }) .
\end{aligned}
$$

Based on that, we can describe satisfaction with two sets of intensity $U=\left\{U^{+}, U^{-}, U^{\circ}\right\}$ and capacity $V=\left\{V^{+}, V^{-}, V^{0}\right\}$. Intensity and capacity can be calculated for a system of determinations, see, for example, Lind and Kuusik (2008). That allows us to have characteristics average for united groups and average for all questions.

In this paper we demonstrate the methodology of determinacy analysis on the example of the survey that conducted by sociologists of Tomsk State University in 2012 in one of the districts of Tomsk Oblast (Russia). The purpose of the survey was to study satisfaction of the population of the district with the functioning of local Administration and municipal services. The study was conducted as a formalized "face to face" interview with the inhabitants of the main settlements. Sample size was 567 people, $5.3 \%$ of the total number of voters of the district. There were $49 \%$ of men, and $51 \%$ of women. The percent of age group 18-34 years was 30\%, 39\% of respondents were from 35 to 54 years old, and $31 \%$ were over 55 years old. The sample size was calculated on the basis of the official information on the number of voters in the district as of July 1, 2012.

The answers of respondents were recorded in the interview forms (questionnaires), which contain information about the satisfaction of the population with local authorities and municipal services. The list of the survey questions was as follows.

1. How the life level has changed in the region over the last year in your opinion? It has improved, deteriorated or remained unchanged?

2. How do you evaluate the Head of the District?

3. Are you satisfied with the activity of the District Administration?

4. Is there enough information provided about the work of the District Administration?

5. Are you satisfied with the work of the Duma (local representative body)?

6. How do you evaluate the Head of your settlement? 
7. Are you satisfied with the quality of health care that hospitals provide in your settlement?

8. Are you satisfied with the quality of education, which is provided in the schools of your settlement?

9. Are you satisfied with the quality of preschool education in kindergartens of your settlement?

10. Are you satisfied with the quality of supplementary education for children in the clubs, art schools, music schools, etc.?

11. Are you satisfied with the quality of cultural services that provide cultural institutions of your settlement?

12. Are you satisfied with the housing and communal services?

13. Age: 1 - from 18 to 34 years old (young), 2 - from 35 to 54 years (senior), 3 - over 55 years (old).

14. Gender: 1 - male 2 - female.

Questions 1-12 supposed to have one of the three optional answers - positive, negative, and neutral (assessment, $n=12)$. Questions 13 and 14 were used to identify groups of respondents $(m=2)$.

In the table 1 we present the intensity of determinations "group $\rightarrow$ assessment". We indicate context in the table with the pair of digitized answers to the questions 13 and 14 , for example, $(1,2)$ means the group of young women, $\left(2,{ }^{*}\right)$ indicates the group of all senior people. For the convenience of the reader, we have identified the maximum value in each row with the bold font, and the minimum value in the row is underlined. In order to simplify referencing to the elements of the table we numbered both rows and columns. Let us note that the last three rows 34-36 correspond to universal context, with no particular group of respondents. All numbers in the table are rounded to two decimal places, which is the reason why sometimes the sum of three intensities is not equal exactly to 1 as expected and should be (see for example, column 1 rows 1-3).

Table 1. Intensity of determinations "group $\rightarrow$ assessment".

\begin{tabular}{|c|c|c|c|c|c|c|c|c|c|c|c|c|c|c|c|}
\hline & \multirow{2}{*}{ Context } & \multirow{2}{*}{ Intensity } & \multicolumn{13}{|c|}{ Survey questions } \\
\hline & & & 1 & 2 & 3 & 4 & 5 & 6 & 7 & 8 & 9 & 10 & 11 & 12 & All \\
\hline No & & & 1 & 2 & 3 & 4 & 5 & 6 & 7 & 8 & 9 & 10 & 11 & 12 & 13 \\
\hline 1 & young & $U+$ & 0.31 & 0.30 & 0.28 & 0.37 & 0.22 & 0.28 & 0.34 & 0.28 & 0.41 & 0.25 & 0.19 & 0.36 & 0.30 \\
\hline 2 & male & U- & 0.20 & 0.18 & 0.33 & 0.36 & 0.22 & 0.02 & 0.47 & 0.10 & 0.05 & 0.10 & 0.23 & 0.20 & 0.20 \\
\hline 3 & $(1,1)$ & Uo & 0.48 & 0.52 & 0.40 & 0.27 & 0.57 & 0.70 & 0.19 & 0.63 & 0.54 & 0.65 & 0.58 & 0.43 & 0.50 \\
\hline 4 & senior & $U+$ & 0.30 & 0.26 & 0.28 & 0.44 & 0.23 & 0.26 & 0.26 & 0.39 & 0.21 & 0.30 & 0.26 & 0.34 & 0.29 \\
\hline 5 & male & U- & 0.21 & 0.19 & 0.32 & 0.36 & 0.21 & 0.04 & 0.49 & 0.04 & 0.04 & 0.06 & 0.15 & 0.27 & 0.20 \\
\hline 6 & $(2,1)$ & Uo & 0.49 & 0.55 & 0.40 & 0.21 & 0.56 & 0.70 & 0.25 & 0.57 & 0.76 & 0.64 & 0.59 & 0.39 & 0.51 \\
\hline 7 & old & $U_{+}$ & 0.27 & 0.28 & 0.31 & 0.46 & 0.13 & 0.24 & 0.38 & 0.28 & 0.09 & 0.20 & 0.22 & 0.29 & 0.26 \\
\hline 8 & male & U- & 0.24 & 0.18 & 0.40 & 0.27 & 0.26 & 0.05 & 0.41 & 0.05 & 0.02 & 0.01 & 0.09 & 0.27 & 0.19 \\
\hline 9 & $(3,1)$ & Uo & 0.49 & 0.54 & 0.29 & 0.27 & 0.61 & 0.72 & 0.21 & 0.67 & 0.88 & 0.79 & 0.68 & 0.44 & 0.55 \\
\hline 10 & all & $U_{+}$ & 0.29 & 0.28 & 0.29 & 0.43 & 0.20 & 0.26 & 0.32 & 0.32 & 0.23 & 0.25 & 0.23 & 0.33 & 0.29 \\
\hline 11 & male & U- & 0.22 & 0.18 & 0.35 & 0.33 & $\overline{0.23}$ & 0.04 & 0.46 & 0.06 & 0.04 & 0.05 & 0.16 & 0.25 & 0.20 \\
\hline 12 & $\left({ }^{*}, 1\right)$ & Uo & 0.49 & 0.54 & 0.37 & 0.24 & 0.58 & 0.71 & 0.22 & 0.62 & 0.73 & 0.69 & 0.61 & 0.42 & 0.52 \\
\hline 13 & young & $U_{+}$ & 0.37 & 0.26 & 0.28 & 0.41 & 0.16 & 0.33 & $\overline{0.44}$ & 0.44 & 0.37 & 0.40 & 0.36 & 0.42 & 0.35 \\
\hline 14 & female & $U$ & 0.15 & 0.10 & 0.30 & 0.33 & 0.21 & 0.02 & 0.49 & 0.07 & 0.09 & 0.05 & 0.19 & 0.16 & 0.18 \\
\hline 15 & $(1,2)$ & Uo & 0.48 & 0.64 & 0.42 & 0.27 & 0.63 & 0.65 & 0.07 & 0.49 & 0.53 & 0.56 & 0.45 & 0.42 & 0.47 \\
\hline 16 & senior & $U_{+}$ & 0.27 & 0.22 & 0.24 & 0.41 & 0.18 & 0.26 & 0.38 & 0.39 & 0.17 & 0.30 & 0.38 & 0.44 & 0.30 \\
\hline 17 & female & $U$ & 0.28 & 0.21 & 0.35 & 0.42 & 0.19 & 0.04 & 0.51 & 0.07 & 0.03 & 0.11 & 0.18 & 0.24 & 0.22 \\
\hline 18 & $(2,2)$ & Uo & 0.45 & 0.57 & 0.42 & 0.18 & 0.64 & 0.71 & 0.11 & 0.54 & 0.81 & 0.59 & 0.44 & 0.32 & 0.48 \\
\hline 19 & old & $U_{+}$ & 0.32 & 0.22 & 0.25 & 0.35 & 0.20 & 0.29 & 0.43 & 0.18 & 0.10 & 0.16 & 0.25 & 0.37 & 0.26 \\
\hline 20 & female & $U$ & 0.11 & 0.08 & 0.39 & 0.35 & 0.16 & 0.05 & 0.41 & 0.02 & 0.01 & 0.02 & 0.12 & 0.29 & 0.17 \\
\hline 21 & $(3,2)$ & Uo & 0.57 & 0.71 & 0.37 & 0.29 & 0.63 & 0.66 & 0.16 & 0.80 & 0.89 & 0.82 & 0.63 & 0.34 & 0.57 \\
\hline 22 & all & $U_{+}$ & 0.32 & 0.23 & 0.25 & 0.39 & 0.18 & 0.29 & 0.41 & 0.34 & 0.21 & 0.28 & 0.33 & 0.41 & 0.30 \\
\hline 23 & female & $U$ & 0.19 & 0.14 & 0.35 & 0.37 & 0.18 & 0.04 & 0.47 & 0.05 & 0.04 & 0.06 & 0.16 & 0.23 & 0.19 \\
\hline 24 & $\left({ }^{\star}, 2\right)$ & Uo & 0.50 & 0.63 & 0.40 & 0.24 & 0.63 & 0.67 & 0.11 & 0.61 & 0.75 & 0.65 & 0.51 & 0.36 & 0.51 \\
\hline 25 & all & $U_{+}$ & 0.34 & 0.28 & 0.28 & 0.39 & 0.19 & 0.30 & 0.39 & 0.36 & 0.39 & 0.33 & 0.28 & 0.39 & 0.33 \\
\hline 26 & young & $U$ & 0.18 & 0.14 & 0.31 & 0.34 & 0.21 & 0.02 & 0.48 & 0.08 & 0.07 & 0.07 & 0.21 & 0.18 & 0.19 \\
\hline 27 & $(1, *)$ & Uo & 0.48 & 0.58 & 0.41 & 0.27 & 0.60 & 0.67 & 0.13 & 0.56 & 0.54 & 0.60 & 0.51 & 0.43 & 0.48 \\
\hline 28 & all & $U_{+}$ & 0.28 & 0.24 & 0.26 & 0.42 & 0.20 & 0.26 & 0.32 & 0.39 & 0.19 & 0.30 & 0.32 & 0.39 & 0.30 \\
\hline 29 & senior & $U-$ & 0.25 & 0.20 & 0.33 & 0.39 & 0.20 & 0.04 & 0.50 & 0.05 & 0.03 & 0.08 & 0.16 & 0.25 & 0.21 \\
\hline 30 & $\left(2,{ }^{*}\right)$ & Uo & 0.47 & 0.56 & 0.41 & 0.19 & 0.60 & 0.70 & $\underline{0.18}$ & 0.55 & 0.78 & 0.62 & 0.51 & 0.35 & 0.49 \\
\hline 31 & all & $U_{+}$ & 0.30 & 0.25 & 0.28 & 0.40 & 0.17 & 0.26 & $\overline{0.40}$ & 0.23 & 0.10 & 0.18 & 0.24 & 0.33 & 0.26 \\
\hline 32 & old & $U-$ & 0.17 & 0.12 & 0.39 & 0.31 & 0.21 & 0.05 & 0.41 & 0.03 & $\overline{0.02}$ & 0.02 & 0.11 & 0.28 & 0.18 \\
\hline 33 & $\left(3,{ }^{*}\right)$ & Uo & 0.53 & 0.63 & 0.33 & 0.28 & 0.62 & 0.69 & 0.19 & 0.74 & 0.89 & 0.80 & 0.66 & 0.39 & 0.56 \\
\hline 34 & & $U_{+}$ & 0.31 & 0.25 & 0.27 & 0.41 & $\underline{0.19}$ & 0.27 & 0.37 & 0.33 & 0.22 & 0.27 & 0.28 & 0.37 & 0.30 \\
\hline 35 & all & U- & 0.20 & 0.16 & 0.35 & 0.35 & $\overline{0.20}$ & $\underline{0.04}$ & 0.47 & 0.06 & $\underline{0.04}$ & 0.06 & 0.16 & 0.24 & 0.19 \\
\hline 36 & $\left({ }^{*}, *\right)$ & Uo & 0.49 & 0.59 & 0.38 & 0.24 & 0.61 & 0.69 & 0.17 & 0.61 & 0.74 & 0.67 & 0.56 & 0.39 & 0.51 \\
\hline
\end{tabular}


The table 1 contains a variety of information about the satisfaction and dissatisfaction with the municipal services, and many of its elements can be used as the basis for conclusions. The intensity-based analysis corresponds to the classical scheme of processing the digitized table of questionnaires. We will give some conclusions based on the table 1 data in the comparative analysis later, and now we proceed to the presentation of the extended scheme of the processing.

\section{Extended Scheme of Processing}

As mentioned above, the intensity of determination provides quantitative characteristic of the investigated correspondence between group and assessment. It gives the proportion of the people from the given group that experiencing the satisfaction (dissatisfaction, indifference) with the work outcomes of the district Administration and municipal services. No doubt that this information is important and useful. But it is equally (if not more) important to obtain information about the structure of assessment of the particular service, i.e. to answer the question "what percent of satisfied (dissatisfied, indifferent) people belong the particular group?" The answer is provided by the capacity of determination. Comparison of different services in terms of their structure can give obviously valuable information on the community opinion.

Such capacities are presented in the table 2. Highlighting of cells (bold and underline) and numbering of rows and columns were made with the same purpose as in the table 1.

Table 2. Capacity of determinations "group $\rightarrow$ assessment".

\begin{tabular}{|c|c|c|c|c|c|c|c|c|c|c|c|c|c|c|c|}
\hline & \multirow{2}{*}{ Capasity } & & \multicolumn{13}{|c|}{ Survey questions } \\
\hline & & & 1 & 2 & 3 & 4 & 5 & 6 &  & 8 & 9 & 10 & 11 & 12 & All \\
\hline No & & & 1 & 2 & 3 & 4 & 5 & 6 & 7 & 8 & 9 & 10 & 11 & 12 & 13 \\
\hline 1 & & young male & 0.15 & \begin{tabular}{|l|l|}
0.17 \\
\end{tabular} & 0.15 & 0.13 & \begin{tabular}{|l|l|}
0.17 \\
\end{tabular} & 0.15 & 0.13 & 0.12 & 0.27 & 0.14 & 0.10 & 0.14 & 0.15 \\
\hline 2 & & senior male & 0.18 & 0.19 & 0.20 & 0.20 & 0.23 & 0.18 & $\underline{0.13}$ & 0.22 & 0.18 & 0.21 & $\overline{0.18}$ & 0.17 & 0.19 \\
\hline 3 & & \begin{tabular}{|l|} 
old male \\
\end{tabular} & 0.13 & 0.17 & 0.17 & 0.17 & 0.10 & 0.13 & $\overline{0.15}$ & 0.13 & 0.06 & 0.11 & 0.12 & 0.12 & 0.13 \\
\hline 4 & & \begin{tabular}{|l} 
young female \\
\end{tabular} & 0.18 & 0.15 & 0.16 & 0.15 & $\underline{0.13}$ & 0.18 & 0.18 & 0.20 & $\overline{0.26}$ & 0.22 & 0.19 & 0.17 & 0.18 \\
\hline 5 & & senior female & 0.17 & 0.17 & 0.18 & 0.20 & 0.19 & 0.19 & 0.21 & 0.23 & 0.15 & 0.22 & 0.27 & 0.24 & 0.20 \\
\hline 6 & $v_{+}$ & \begin{tabular}{|l|} 
old female \\
\end{tabular} & 0.17 & 0.14 & 0.15 & 0.14 & 0.18 & 0.17 & 0.19 & 0.09 & 0.07 & 0.10 & 0.14 & 0.16 & 0.14 \\
\hline 7 & & all male & 0.47 & 0.53 & 0.52 & 0.51 & 0.50 & 0.46 & 0.42 & \begin{tabular}{|l|l|}
0.47 \\
\end{tabular} & 0.52 & 0.46 & 0.39 & 0.43 & \begin{tabular}{|l|l}
0.47 \\
\end{tabular} \\
\hline 8 & & all female & 0.53 & 0.47 & 0.48 & 0.49 & 0.50 & 0.54 & 0.58 & 0.53 & 0.48 & 0.54 & 0.61 & 0.57 & 0.53 \\
\hline 9 & & \begin{tabular}{|l|} 
all young \\
\end{tabular} & 0.34 & $\overline{0.33}$ & 0.31 & 0.29 & 0.30 & 0.33 & 0.32 & 0.32 & 0.53 & 0.36 & 0.29 & 0.31 & 0.34 \\
\hline 10 & & all senior & 0.36 & 0.37 & 0.37 & $\overline{0.40}$ & 0.42 & 0.37 & 0.34 & 0.46 & 0.33 & 0.43 & $\overline{0.44}$ & 0.41 & 0.39 \\
\hline 11 & & all old & 0.31 & 0.31 & 0.32 & 0.31 & 0.28 & 0.30 & 0.34 & 0.22 & 0.14 & 0.21 & 0.26 & 0.28 & 0.27 \\
\hline 12 & & young male & 0.15 & 0.17 & 0.14 & 0.15 & 0.16 & 0.10 & 0.15 & 0.25 & $\overline{0.18}$ & 0.24 & 0.21 & 0.12 & \begin{tabular}{|l|l}
0.17 \\
\end{tabular} \\
\hline 13 & & senior male & 0.20 & $\mid 0.22$ & 0.17 & 0.19 & 0.19 & $\overline{0.19}$ & 0.20 & 0.13 & $\mid 0.18$ & 0.18 & 0.18 & 0.21 & 0.19 \\
\hline 14 & & old male & 0.17 & 0.17 & 0.17 & 0.12 & 0.19 & 0.19 & 0.13 & 0.13 & 0.09 & $\underline{0.03}$ & 0.09 & 0.17 & 0.14 \\
\hline 15 & & young female & 0.11 & 0.10 & 0.13 & 0.14 & 0.16 & 0.10 & 0.16 & 0.19 & 0.36 & $\overline{0.12}$ & 0.18 & 0.10 & 0.15 \\
\hline 16 & & senior female & 0.28 & $\overline{0.27}$ & 0.20 & 0.24 & 0.18 & $\overline{0.19}$ & 0.22 & 0.25 & 0.14 & 0.36 & 0.22 & $\overline{0.20}$ & 0.23 \\
\hline 17 & V- & \begin{tabular}{|l|} 
old female \\
\end{tabular} & 0.09 & 0.08 & 0.18 & 0.17 & 0.13 & 0.24 & 0.14 & 0.06 & $\underline{0.05}$ & 0.06 & 0.12 & 0.20 & 0.13 \\
\hline 18 & & all male & 0.52 & 0.56 & 0.48 & 0.46 & 0.53 & 0.48 & 0.48 & 0.50 & $\overline{0.45}$ & 0.45 & 0.48 & 0.50 & 0.49 \\
\hline 19 & & \begin{tabular}{|l|l|l|} 
all female \\
\end{tabular} & 0.48 & 0.44 & 0.52 & 0.54 & 0.47 & 0.52 & 0.52 & 0.50 & $\overline{0.55}$ & $\overline{0.55}$ & 0.52 & 0.50 & 0.51 \\
\hline 20 & & all young & 0.26 & 0.27 & 0.27 & 0.29 & 0.31 & 0.19 & 0.31 & 0.44 & 0.55 & 0.36 & 0.39 & 0.23 & 0.32 \\
\hline 21 & & all senior & 0.48 & 0.49 & 0.37 & 0.43 & 0.37 & $\overline{0.38}$ & 0.42 & 0.38 & 0.32 & 0.55 & 0.40 & 0.41 & 0.42 \\
\hline 22 & & \begin{tabular}{|l|l|} 
all old \\
\end{tabular} & 0.26 & 0.24 & 0.36 & 0.28 & 0.32 & 0.43 & 0.28 & 0.19 & $\overline{0.14}$ & 0.09 & 0.21 & 0.36 & 0.26 \\
\hline 23 & & young male & 0.14 & 0.13 & 0.15 & 0.16 & 0.14 & 0.15 & 0.17 & 0.15 & 0.11 & 0.14 & 0.15 & 0.16 & 0.15 \\
\hline 24 & & senior male & 0.19 & 0.18 & 0.20 & 0.16 & 0.17 & 0.19 & 0.29 & 0.18 & $\overline{0.19}$ & 0.18 & 0.20 & 0.19 & 0.19 \\
\hline 25 & & \begin{tabular}{|l|} 
old male \\
\end{tabular} & 0.15 & 0.14 & 0.11 & $\overline{0.17}$ & 0.15 & 0.16 & 0.19 & 0.16 & $\mid 0.18$ & 0.18 & 0.18 & 0.17 & 0.16 \\
\hline 26 & & young female & 0.15 & 0.17 & 0.17 & 0.17 & 0.16 & 0.14 & 0.06 & 0.12 & $\mid 0.11$ & 0.13 & 0.12 & 0.16 & 0.14 \\
\hline 27 & & senior female & 0.18 & 0.19 & 0.22 & 0.15 & 0.21 & 0.20 & $\overline{0.13}$ & 0.18 & 0.22 & 0.18 & 0.16 & 0.16 & 0.18 \\
\hline 28 & vo & \begin{tabular}{|l|} 
old female \\
\end{tabular} & 0.19 & 0.20 & 0.16 & 0.20 & 0.17 & 0.16 & $\overline{0.16}$ & 0.21 & 0.20 & 0.20 & 0.19 & 0.15 & 0.18 \\
\hline 29 & & all male & 0.48 & 0.44 & 0.46 & 0.49 & 0.46 & 0.50 & 0.65 & 0.49 & \begin{tabular}{|l|l|}
0.48 \\
\end{tabular} & 0.50 & 0.53 & 0.53 & 0.50 \\
\hline 30 & & \begin{tabular}{|l|l|l} 
all female \\
\end{tabular} & 0.52 & $\overline{0.56}$ & 0.54 & 0.51 & 0.54 & 0.50 & 0.35 & 0.51 & 0.52 & 0.50 & 0.47 & 0.47 & 0.50 \\
\hline 31 & & all young & 0.29 & 0.29 & \begin{tabular}{|l|}
0.32 \\
\end{tabular} & 0.33 & 0.29 & 0.29 & $\overline{0.23}$ & \begin{tabular}{|l|}
0.27 \\
\end{tabular} & 0.22 & 0.27 & 0.27 & 0.33 & 0.28 \\
\hline 32 & & all senior & 0.37 & 0.37 & 0.41 & 0.31 & 0.38 & 0.40 & 0.41 & 0.35 & 0.41 & 0.36 & 0.36 & 0.36 & 0.37 \\
\hline 33 & & \begin{tabular}{|l|l|} 
all old \\
\end{tabular} & 0.34 & 0.34 & 0.27 & $\overline{0.36}$ & 0.32 & 0.31 & 0.35 & 0.38 & 0.38 & 0.38 & 0.37 & 0.32 & 0.34 \\
\hline
\end{tabular}

There are many ways to study the information in tables 1 and 2, depending on the initial hypothesis that is necessary to 
confirm or reject. For example, consider the following approach. Let us put to the separate table 3 the numbers of the survey questions (i.e. provided public service), which received the minimal and maximal intensity and capacity in different gender and age contexts.

Table 3. Numbers of questions received minimal and maximal intensity and capacity of determinations «group $\rightarrow$ assessment».

\begin{tabular}{|c|c|c|c|c|c|c|c|c|c|c|c|c|}
\hline \multirow{3}{*}{ Group } & \multicolumn{6}{|c|}{ Intensity (see table 1) } & \multicolumn{6}{|c|}{ Capacity (see table 2) } \\
\hline & \multicolumn{2}{|c|}{ satisfaction } & \multicolumn{2}{|c|}{ dissatisfaction } & \multicolumn{2}{|c|}{ indifference } & \multicolumn{2}{|c|}{ satisfaction } & \multicolumn{2}{|c|}{ dissatisfaction } & \multicolumn{2}{|c|}{ indifference } \\
\hline & $\min$ & $\max$ & $\min$ & $\max$ & $\min$ & $\max$ & $\min$ & $\max$ & $\min$ & $\max$ & $\min$ & $\max$ \\
\hline young men $(1,1)$ & 11 & 9 & 6 & 7 & 7 & 6 & 11 & 9 & 6 & 8 & 9 & 7 \\
\hline senior men $(2,1)$ & 9 & 4 & $6,8,9$ & 7 & 4 & 9 & 7 & 5 & 8 & 2 & 4 & 7 \\
\hline old men $(3,1)$ & 9 & 4 & 10 & 7 & 7 & 9 & 9 & $2,3,4$ & 10 & 5,6 & 3 & 7 \\
\hline all men $\left({ }^{*}, 1\right)$ & 5 & 4 & 6,9 & 7 & 7 & 9 & 11 & 2 & 9,10 & 2 & 2 & 7 \\
\hline young women $(1,2)$ & 5 & 7,8 & 6,9 & 7 & 7 & 6 & 5 & 9 & $2,6,12$ & 9 & 7 & $2,3,4$ \\
\hline senior women $(2,2)$ & 9 & 12 & 9 & 7 & 7 & 9 & 9 & 11 & 9 & 10 & 7 & 3,9 \\
\hline old women $(3,2)$ & 9 & 7 & 9 & 7 & 7 & 9 & 9 & 7 & 9 & 6 & 12 & 8 \\
\hline all women $\left({ }^{*}, 2\right)$ & 5 & 7 & 6,9 & 7 & 7 & 6 & 2 & 11 & 2 & 9,10 & 7 & 2 \\
\hline all young $\left(1,{ }^{*}\right)$ & 5 & $4,7,9,12$ & 6 & 7 & 7 & 6 & 4,11 & 9 & 6 & 9 & 9 & 4,12 \\
\hline all senior $\left(2,{ }^{*}\right)$ & 9 & 4 & 9 & 7 & 7 & 9 & 9 & 8 & 9 & 10 & 4 & $3,7,9$ \\
\hline all old $\left(3,{ }^{*}\right)$ & 9 & 4,7 & 9,10 & 7 & 7 & 9 & 9 & 7 & 10 & 6 & 3 & $8,9,10$ \\
\hline all $(*, *)$ & 5 & 4 & 6,9 & 7 & 7 & 9 & & & & & & \\
\hline
\end{tabular}

Studying the table 3 we see a common dissatisfaction with the medical services in the district (see question 7 by intensity), male population most indifferent in that issue unlike women population (question 7 by capacity). Preschool education is assessed noticeably indifferent by senior and old inhabitants (question 9 by intensity and capacity), despite of the activity of young people in that issue (question 9 by capacity). The level of provided information about activities of local Administration (question 4) is appreciated by the population in average mostly due to the male inhabitants. Young men and women are definitely indifferent to the Head of their village (question 6 by intensity and capacity). The analysis may continue by similar way.

Now let us return to initial tables 1 and 2 and investigate the structure of the assessments. We will need a referencing to the elements of the tables. Let us use the references in the form of three numbers: \{\#table, \#row, \#column\}.

First of all, we should note the high level of average indifference that observed at the line 36 of table 1 concerning to questions 1, 2, 5, 6, 8-11. Only four questions about local Administration activities (questions 3, 4), health care (question 7), and housing (question 12) services attracted a noticed attention of the most of inhabitants.

Analyzing distribution of capacities by groups, we can detect maximal contribution to the assessment from the side of some groups. For example, we can see (at the range of cells $\{2,7-8,7\}$ ) the noticeable impact of women to formation of positive part of assessment of the health care. Senior people much more frequently express negative attitude to the medical services than young and old groups (see the range $\{2,20-22,7\}$ ). Male population is much more indifferent to the medical care than women (range $\{2,29-30,7\}$ ).

Consider the question 9 (quality of pre-school education). Most active in the assessment of that service are expectably young men and women both by positive (see ranges $\{2,1-6,9\},\{2,9-11,9\}$ ) and negative (range $\{2,20-22$, 9\}) way. Also they are less indifferent (range $\{2,34-36,9\}$ ). At the same time young men are not tending to assess the service negatively (range $\{2,12-17,9\}$ ) in contrast with young women.

Question 4 (availability of information about the activities of local Administration) demonstrates non-uniform assessment from the different groups. Positive assessment is more frequently comes from senior citizens (ranges $\{2,1-6$, $4\}$ and $\{2,9-11,4\}$ ). They also are more active in the negative assessment (ranges $\{2,12-17,4\}$ and $\{2,20-22,4\}$ ) than young and old groups of the population.

Even in the question 11 (assessment of cultural institutions), that was not very interesting for more than half of population (see cell $\{1,36,11\}$ ) we can find non-uniform distribution of positive assessment between the men and women groups (see range $\{2,7-8,11\}$ ).

Analogous approach can be applied to each question of the survey. 


\section{Significance of Responses}

Thinking about the issue of possible imperfection of the data processing method, we understand that, for example, the reason of negative assessment can be not only in failures of the Administration and municipal services, but also in imperfection of survey methods and mathematical processing of the results.

We drew attention to the fact that the above described method considers opinions of all respondents as equally significant, regardless of gender, age, and their acquaintance with the assessed issue. Is it fair to equate opinion about medicine that came from the young person, who almost not using the medical services, and from the old person, who needs health care almost every day? It was the starting point for the idea to take into account in the calculation of satisfaction (dissatisfaction, indifference) the importance of the opinions of respondents on each survey question.

Following this idea, we introduce weighted (adjusted) intensity and capacity by the formulae

$I(a \rightarrow b)=\frac{W(a b)}{W(a)}$ and $C(a \rightarrow b)=\frac{W(a b)}{W(b)}$,

which is generalizing formulae (1) by replacement the regular amount $n(\cdot)$ with scores $W(\cdot)$, where

$W(a b)=\sum_{i=1}^{N} w\left(x_{i}\right) \chi_{a}\left(x_{i}\right) \chi_{b}\left(x_{i}\right)$,

$W(a)=\sum_{i=1}^{N} w\left(x_{i}\right) \chi_{a}\left(x_{i}\right)$

$W(b)=\sum_{i=1}^{N} w\left(x_{i}\right) \chi_{b}\left(x_{i}\right)$,

$N$ is the total number of respondents (sample size), $x_{i}$ is the $i$-th respondent, $w\left(x_{i}\right)$ is individual significance of the respondent answer to the given question, $\chi_{a}\left(x_{i}\right)$ is indicator function that takes value 1 if the respondent $x_{i}$ has the property a and $\chi_{a}\left(x_{i}\right)=0$ otherwise.

Note that if all responses are equally significant, i.e. $w\left(x_{i}\right) \equiv 1$, then the score equals to regular amount, i.e. $W(\cdot)=n(\cdot)$ and we have regular intensity and capacity (1) as the special case of (2).

In the table 4 we suggest a trial version of evaluation of the group significance for each survey question. This approach means that individual significance coefficients are equal for all respondents that belong to the same group.

Table 4. Significance coefficients.

\begin{tabular}{|c|c|c|c|c|c|c|}
\hline \multirow{2}{*}{ Survey question } & \multicolumn{7}{|c|}{ Group } \\
\cline { 2 - 7 } & Young men & Senior men & Old men & Young women & Senior women & Old women \\
\hline 1 & 2 & 3 & 1 & 2 & 3 & 1 \\
2 & 2 & 3 & 1 & 2 & 3 & 1 \\
3 & 2 & 3 & 1 & 2 & 3 & 1 \\
4 & 1 & 2 & 1 & 1 & 2 & 1 \\
5 & 1 & 2 & 1 & 1 & 2 & 1 \\
6 & 1 & 2 & 3 & 1 & 2 & 3 \\
7 & 1 & 2 & 3 & 1 & 2 & 3 \\
8 & 3 & 2 & 1 & 3 & 2 & 1 \\
9 & 3 & 2 & 1 & 3 & 2 & 1 \\
10 & 2 & 2 & 1 & 2 & 2 & 1 \\
11 & 3 & 2 & 1 & 3 & 2 & 1 \\
12 & 2 & 3 & 1 & 2 & 3 & 1 \\
\hline
\end{tabular}

Tables 5 and 6 show the intensity and capacity of determinations with taking into account the importance of the groups from table 4. Studying these tables one can do many useful conclusions.

In the analysis of tables 1 and 5, we should take into account, that weighted and un-weighted intensity are equal within all low level gender and age contexts (they omitted in table 5). This is because of only one coefficient of significance is using in both numerator and denominator of the intensity ratio at that cases. Also in the table 4 significance coefficients are independent of gender, that implies equality of weighted and un-weighted intensities calculated within contexts $\left(1,{ }^{*}\right),\left(2,{ }^{*}\right),\left(3,{ }^{*}\right)$. All rows of table 5 that coincide with data from table 1 are omitted, but the initial row numbering is not changed. 
Table 5. Intensity of determinations "group $\rightarrow$ assessment" calculated with significance coefficients.

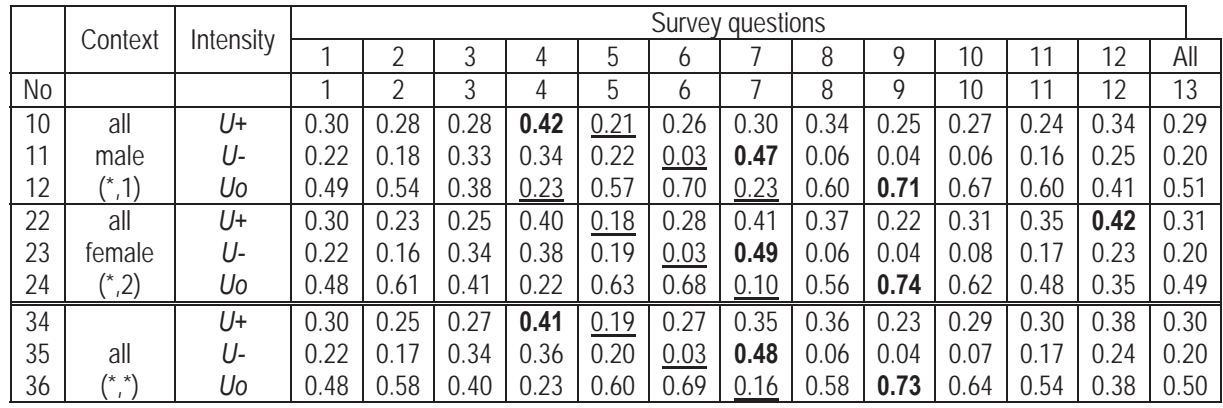

The difference in question numbers with extreme values of intensity (tables 1 and 5) and capacity (tables 2 and 6) is shown in table 7 and discussed below.

We should note that the approach to assigning the significance coefficients that described above is obviously subjective. One of the possible ways to eliminate the researcher subjectivism is asking respondents to evaluate significance of their answer to each question. One of the possible approaches in the case of a service assessment is to ask additional questions: "Have you used this service?" and "Do you have enough information about this service?" It is natural to measure the significance of the responses of a respondent $x_{i}$ by usage of the rule: responses (no, no) correspond to significance coefficient $w\left(x_{i}\right)=1$, the answers (no, yes) correspond to $w\left(x_{i}\right)=2$, (yes, no) to 3 , and (yes, yes) to 4. Thus, along with the responses to the questionnaire the respondents give us their own assessment of the significance of their answers. The proposed method of self-evaluation makes the survey procedure more complicated. However, the produced information about the community opinion is much more important.

Table 6. Capacity of determinations "group $\rightarrow$ assessment" calculated with significance coefficients.

\begin{tabular}{|c|c|c|c|c|c|c|c|c|c|c|c|c|c|c|c|}
\hline & \multirow{2}{*}{ Capasity } & & \multicolumn{13}{|c|}{ Survey questions } \\
\hline & & & 1 & 2 & 3 & 4 & 5 & 6 & 7 & 8 & 9 & 10 & 11 & 12 & All \\
\hline No & & & 1 & 2 & 3 & 4 & 5 & 6 & 7 & 8 & 9 & 10 & 11 & 12 & 13 \\
\hline 1 & \multirow{11}{*}{ V+ } & young male & 0.15 & 0.17 & 0.15 & 0.13 & 0.16 & 0.14 & 0.13 & 0.11 & 0.25 & 0.12 & $\underline{0.09}$ & 0.13 & 0.14 \\
\hline 2 & & senior male & 0.27 & 0.28 & 0.29 & 0.29 & 0.33 & 0.26 & $\underline{0.20}$ & 0.30 & 0.24 & 0.28 & 0.24 & 0.24 & 0.27 \\
\hline 3 & & old male & 0.06 & 0.08 & 0.08 & 0.08 & 0.05 & 0.06 & 0.08 & 0.06 & $\underline{0.03}$ & 0.05 & 0.05 & 0.06 & 0.06 \\
\hline 4 & & young female & 0.18 & 0.15 & 0.15 & 0.14 & $\underline{0.12}$ & 0.18 & 0.18 & 0.18 & 0.24 & 0.20 & 0.18 & 0.16 & 0.17 \\
\hline 5 & & senior female & 0.25 & 0.25 & 0.26 & 0.29 & 0.26 & 0.27 & 0.31 & 0.31 & $\underline{0.21}$ & 0.30 & 0.37 & 0.33 & 0.28 \\
\hline 6 & & old female & 0.08 & 0.07 & 0.07 & 0.07 & 0.08 & 0.08 & 0.10 & 0.04 & $\underline{0.03}$ & 0.04 & 0.07 & 0.08 & 0.07 \\
\hline 7 & & all male & 0.48 & 0.53 & 0.52 & 0.50 & 0.53 & 0.47 & 0.41 & 0.47 & 0.52 & 0.46 & $\underline{0.39}$ & 0.43 & 0.48 \\
\hline 8 & & all female & 0.52 & $\underline{0.47}$ & 0.48 & 0.50 & $\underline{0.47}$ & 0.53 & 0.59 & 0.53 & 0.48 & 0.54 & 0.61 & 0.57 & 0.52 \\
\hline 9 & & all young & 0.33 & 0.32 & 0.30 & $\underline{0.27}$ & 0.28 & 0.32 & 0.32 & 0.29 & 0.49 & 0.32 & $\underline{0.27}$ & 0.29 & 0.32 \\
\hline 10 & & all senior & 0.52 & 0.54 & 0.54 & 0.58 & 0.59 & 0.53 & 0.51 & 0.61 & $\underline{0.45}$ & 0.58 & 0.61 & 0.57 & 0.55 \\
\hline 11 & & all old & 0.15 & 0.15 & 0.16 & 0.15 & 0.13 & 0.15 & 0.17 & 0.10 & $\underline{0.06}$ & 0.09 & 0.12 & 0.13 & 0.13 \\
\hline 12 & \multirow{8}{*}{ V- } & young male & 0.13 & 0.15 & 0.14 & 0.14 & 0.15 & $\underline{0.10}$ & 0.14 & 0.23 & 0.17 & 0.20 & 0.19 & 0.12 & 0.15 \\
\hline 13 & & senior male & 0.27 & 0.30 & 0.26 & 0.27 & 0.28 & 0.29 & 0.28 & $\underline{0.17}$ & 0.25 & 0.22 & 0.24 & 0.31 & 0.26 \\
\hline 14 & & old male & 0.08 & 0.07 & 0.09 & 0.05 & 0.09 & 0.10 & 0.06 & 0.06 & 0.04 & $\underline{0.01}$ & 0.04 & 0.08 & 0.06 \\
\hline 15 & & young female & 0.10 & $\underline{0.09}$ & 0.13 & 0.13 & 0.15 & 0.10 & 0.15 & 0.17 & 0.33 & 0.10 & 0.16 & 0.10 & 0.14 \\
\hline 16 & & senior female & 0.38 & 0.36 & 0.30 & 0.33 & 0.26 & 0.29 & 0.31 & 0.34 & $\underline{0.19}$ & 0.44 & 0.30 & 0.29 & 0.32 \\
\hline 17 & & old female & 0.04 & 0.03 & 0.09 & 0.08 & 0.06 & 0.12 & 0.07 & 0.03 & $\underline{0.02}$ & $\underline{0.02}$ & 0.06 & 0.10 & 0.06 \\
\hline 18 & & all male & 0.48 & 0.52 & 0.48 & 0.46 & 0.52 & 0.49 & 0.48 & 0.46 & 0.46 & $\underline{0.43}$ & 0.48 & 0.51 & 0.48 \\
\hline 19 & & all female & 0.52 & $\underline{0.48}$ & 0.52 & 0.54 & $\underline{0.48}$ & 0.51 & 0.52 & 0.54 & 0.54 & 0.57 & 0.52 & 0.49 & 0.52 \\
\hline
\end{tabular}




\begin{tabular}{|c|c|c|c|c|c|c|c|c|c|c|c|c|c|c|c|}
\hline 20 & & all young & 0.24 & 0.24 & 0.27 & 0.27 & 0.30 & $\underline{0.20}$ & 0.29 & 0.40 & 0.50 & 0.30 & 0.36 & 0.22 & 0.30 \\
\hline 21 & & all senior & 0.65 & 0.65 & 0.55 & 0.60 & 0.54 & 0.59 & 0.58 & 0.51 & $\underline{0.44}$ & 0.67 & 0.55 & 0.60 & 0.58 \\
\hline 22 & & all old & 0.12 & 0.11 & 0.18 & 0.13 & 0.16 & 0.22 & 0.13 & 0.09 & 0.06 & $\underline{0.04}$ & 0.10 & 0.18 & 0.12 \\
\hline 23 & \multirow{11}{*}{ Vo } & young male & 0.14 & 0.13 & 0.14 & 0.17 & 0.13 & 0.14 & 0.16 & 0.15 & $\underline{0.11}$ & 0.14 & 0.15 & 0.16 & 0.14 \\
\hline 24 & & senior male & 0.28 & 0.26 & 0.28 & $\underline{0.25}$ & $\underline{0.25}$ & 0.28 & 0.42 & 0.27 & 0.28 & 0.27 & 0.30 & 0.28 & 0.28 \\
\hline 25 & & old male & 0.07 & 0.07 & $\underline{0.05}$ & 0.09 & 0.07 & 0.07 & 0.09 & 0.08 & 0.09 & 0.09 & 0.09 & 0.08 & 0.08 \\
\hline 26 & & young female & 0.14 & 0.16 & 0.15 & 0.17 & 0.15 & 0.14 & $\underline{0.06}$ & 0.12 & 0.11 & 0.13 & 0.12 & 0.16 & 0.14 \\
\hline 27 & & senior female & 0.27 & 0.28 & 0.30 & 0.23 & 0.30 & 0.29 & $\underline{0.19}$ & 0.27 & 0.32 & 0.27 & 0.24 & 0.24 & 0.27 \\
\hline 28 & & old female & 0.09 & 0.10 & $\underline{0.07}$ & 0.10 & 0.08 & $\underline{0.07}$ & 0.08 & 0.11 & 0.10 & 0.10 & 0.09 & $\underline{0.07}$ & 0.09 \\
\hline 29 & & all male & 0.49 & $\underline{0.46}$ & 0.47 & 0.50 & $\underline{0.46}$ & 0.49 & 0.68 & 0.50 & 0.48 & 0.51 & 0.54 & 0.53 & 0.51 \\
\hline 30 & & all female & 0.51 & 0.54 & 0.53 & 0.50 & 0.54 & 0.51 & $\underline{0.32}$ & 0.50 & 0.52 & 0.49 & 0.46 & 0.47 & 0.49 \\
\hline 31 & & all young & 0.29 & 0.29 & 0.30 & 0.34 & 0.28 & 0.28 & 0.23 & 0.27 & $\underline{0.21}$ & 0.27 & 0.28 & 0.32 & 0.28 \\
\hline 32 & & all senior & 0.55 & 0.55 & 0.58 & $\underline{0.47}$ & 0.56 & 0.57 & 0.60 & 0.53 & 0.60 & 0.54 & 0.54 & 0.52 & 0.55 \\
\hline 33 & & all old & 0.17 & 0.17 & $\underline{0.13}$ & 0.19 & 0.16 & 0.15 & 0.17 & 0.19 & 0.18 & 0.19 & 0.19 & 0.15 & 0.17 \\
\hline
\end{tabular}

The analog of table 3 with extracted question numbers having extreme values of intensity and capacity at tables 5 and 6 , is placed at the table 7. Additionally we highlight with italic font the part of the table 7 which contains items unchanged by definition (as compared to table 3). Also we show bolded those parts of the table 7 that differs from table 3 . The coincidence of question numbers with the maximal and minimal intensities (non-bolded and non-italic numbers) can be seen as confirmation of the characteristics of community opinion detected before in table 3 . The mismatch of the extreme values question numbers (bolded) draws attention to a possible problem with interpretation of the data, which has been detected due to application of individual weights. For example, we can see the new item in table 7: in the structure of positive assessment of the health care the opinion of old men became maximal among others (before weighting, only the old women most frequently expressed positive opinion about medical services).

Table 7. Numbers of questions received minimal and maximal intensity and capacity of determinations «group $\rightarrow$ assessment» calculated with significance coefficients.

\begin{tabular}{|c|c|c|c|c|c|c|c|c|c|c|c|c|}
\hline \multirow{3}{*}{ Group } & \multicolumn{6}{|c|}{ Intensity (see table 5) } & \multicolumn{6}{|c|}{ Capacity (see table 6) } \\
\hline & \multicolumn{2}{|c|}{ satisfaction } & \multicolumn{2}{|c|}{ dissatisfaction } & \multicolumn{2}{|c|}{ indifference } & \multicolumn{2}{|c|}{ satisfaction } & \multicolumn{2}{|c|}{ dissatisfaction } & \multicolumn{2}{|c|}{ indifference } \\
\hline & $\min$ & $\max$ & $\min$ & $\max$ & $\min$ & $\max$ & $\min$ & $\max$ & $\min$ & $\max$ & $\min$ & $\max$ \\
\hline young men $(1,1)$ & 11 & 9 & 6 & 7 & 7 & 6 & 11 & 9 & 6 & 8 & 9 & 4 \\
\hline senior men $(2,1)$ & 9 & 4 & $6,8,9$ & 7 & 4 & 9 & 7 & 5 & 8 & 12 & 4,5 & 7 \\
\hline old men $(3,1)$ & 9 & 4 & 10 & 7 & 7 & 9 & 9 & $2,3,4,7$ & 10 & 6 & 3 & $4,7,9,10,11$ \\
\hline all men $\left({ }^{*}, 1\right)$ & 5 & 4 & 6 & 7 & 4,7 & 9 & 11 & 2,5 & 10 & 2,5 & 2,5 & 7 \\
\hline young women $(1,2)$ & 5 & 7,8 & 6,9 & 7 & 7 & 6 & 5 & 9 & 2 & 9 & 7 & 4 \\
\hline senior women $(2,2)$ & 9 & 12 & 9 & 7 & 7 & 9 & 9 & 11 & 9 & 10 & 7 & 9 \\
\hline old women $(3,2)$ & 9 & 7 & 9 & 7 & 7 & 9 & 9 & 7 & 9,10 & 6 & $3,6,12$ & 8 \\
\hline all women $\left({ }^{*}, 2\right)$ & 5 & 12 & 6 & 7 & 7 & 9 & 2,5 & 11 & 2,5 & 10 & 7 & 2,5 \\
\hline all young $\left(1,{ }^{*}\right)$ & 5 & $4,7,9,12$ & 6 & 7 & 7 & 6 & 4,11 & 9 & 6 & 9 & 9 & 4 \\
\hline all senior $\left(2,{ }^{*}\right)$ & 9 & 4 & 9 & 7 & 7 & 9 & 9 & 8,11 & 9 & 10 & 4 & 7,9 \\
\hline all old $(3, *)$ & 9 & 4,7 & 9,10 & 7 & 7 & 9 & 9 & 7 & 10 & 6 & 3 & $8,10,11$ \\
\hline all $(*, *)$ & 5 & 4 & 6 & 7 & 7 & 9 & & & & & & \\
\hline
\end{tabular}

\section{Conclusions}

In this paper we have provided arguments for usage of determinacy analysis approach in the processing of a survey data for better description of the structure of the public opinion on the functioning of local government and municipal services.

Among many other possible conditional frequencies, the determinacy analysis uses just the intensities and capacities of determinations as the useful characteristic of described regularities. Interpretation of capacities expands the regular approach to extracting information from the survey data. We were tried to demonstrate advantages of the expansion at the example of the processing of real survey data.

For the future studies on that issue we suggest to include to the questionnaire the additional questions that allow 
evaluating the respondent ability to assess the particular service (response significance coefficients). In this paper we suggested a way for utilization of those coefficients for calculation of the adjusted intensities and capacities.

We also should note that in this paper we did not consider statistical issues of the determinacy analysis, such as accuracy of the intensity and capacity as estimates of conditional probabilities, and hypothesis testing for detection of significant difference between capacities calculated in different contexts. That is a subject for the further research.

\section{Acknowledgement}

This study (research grant No 8.1.98.2015) was supported by The Tomsk State University Academic D.I. Mendeleev Fund Program in 2015.

\section{References}

Chesnokov, S. V. (1982). Determinacy analysis of social-economic data. Moscow: Nauka (in Russian).

Chesnokov, S. V., \& Luelsdorff, P. A. (1991). Determinacy analysis and theoretical orthography. Theoretical Linguistics, 17(1-3).

Cuadrado-Ballesteros B., García-Sánchez Isabel-María, Prado-Lorenzo José-Manuel. (2013). Effect of modes of public services delivery on the efficiency of local governments: A two-stage approach. Utilities Policy, 26 (pp 23-35).

Deininger K., Mpuga P. (2005). Does Greater Accountability Improve the Quality of Public Service Delivery? Evidence from Uganda. World Development, 33 (1), 171-191.

Djellal F., Gallouj F., Miles I. (2013). Two decades of research on innovation in services: Which place for public services? Structural Changes and Economic Dynamics, 27, 98-117.

Dmitriev, Y.G., Martynova, S.E., \& Ustinov, Y.K. (2015). On the validity of quantitative assessment of socium satisfaction with the quality of public services: the case of municipalities of Russia. Proceedings of the 3rd International conference on development of sociology and demography in Eurasia (Vienna, April 20, 2015). "East West" Association for Advanced Studies and Higher Education $\mathrm{GmbH}, 19-26$ (in Russian).

Hoxley, M. (2001). Purchasing UK public sector property and construction professional services: competition v quality. European Journal of Purchasing \& Supply Management. 7, 133-139.

Kolmogorov, A. N. (1956). Foundations of the Theory of Probability. (2nd ed.). New York: Chelsea Pub. Co.

Lind, G., \& Kuusik, R. (2008). New developments for determinacy analysis: diclique-based approach. WSEAS Transactions on Information Science and Applications. 5 (10), 1448-1459.

Luelsdorff, P.A., \& Chesnokov, S.V. (1996). Determinacy form as the essence of language. Prague Linguistic Circle Papers, 2, 205-234.

Martynova, S.E., \& Maslennikova, O.G. (2014). The "service" model of the competences of the municipal employee as a basis of vocational training: Russian experience. Procedia - Social and Behavioral Sciences, 174, 2716-2720.

Purcărea, V.L., Gheorghea I.R., \& Petrescu C.M. (2013). The Assessment of Perceived Service Quality of Public Health Care Services in Romania Using the SERVQUAL Scale. Procedia Economics and Finance, 6, 573-585.

Umegaki, H., Yanagawa, M., Nonogaki, Z., Nakashima, H., Kuzuya, M., \& Endo, H. (2014). Burden reduction of caregivers for users of care services provided by the public long-term care insurance system in Japan. Archives of Gerontology and Geriatrics, 58, 130133. 